\title{
MENGUKUR KUALITAS APLIAKSI GUDANG DENGAN METODE USABILITY NIELSEN
}

\author{
Alam Supriyatna, Rendy Andika \\ Program Studi Sistem Informasi \\ Sekolah Tinggi Ilmu Komputer BINANIAGA \\ Email: alamsupriyatna6429@gmail.com
}

\begin{abstract}
Warehouse application is an application used by employees of PT. Unggul Karya Semesta, to input data of incoming and outgoing goods in the warehouse, content related to information of goods data in warehouse application include goods code, goods data, supliyer, and date of entry and exit of goods. One of the usefulness of this application is to control the data items that come out and enter. Use of this warehouse application is to run an effective business process and function to perform data entry activities. The usability method is used to analyze whether the warehouse application has a good usage level of the application. The purpose of this study is to measure the quality of warehouse applications in PT. Superior works of the universe. The research instrument used is a questionnaire whose results are calculated using the mean / average formula to measure the quality of warehouse applications. From the results of the study known the quality of warehouse applications in PT.Unggul Karya Semesta from learnability parameter obtained value of 3.53 entered in either category, efficiency parameters obtained 3.8 values entered in either category, memorability parameters obtained value 3.81 entered in either category, parameter error obtained value of 2.7 enter in enough category, satisfaction parameter obtained 3.71 into good category
\end{abstract}

Keywords: usability, mean, Warehouse application

\begin{abstract}
ABSTRAK
Aplikasi gudang merupakan aplikasi yang digunakan para karyawan PT. Unggul Karya Semesta, untuk menginput data barang masuk dan keluar di gudang, kontenkonten yang berhubungan dengan informasi data barang di aplikasi gudang tersebut meliputi kode barang, Data barang, supliyer, dan tgl masuk dan keluarnya barang. Salah satu kegunaan aplikasi ini adalah untuk mengontrol data barang yang keluar dan masuk. Peggunaan aplikasi gudang ini adalah untuk menjalankan proses bisnis yang efektif dan berfungsi untuk melakukan kegiatan penginputan data. Metode usability digunakan untuk menganalisis apakah aplikasi gudang ini memiliki tingkat kebergunaan aplikas yang baik. Tujuan dari penelitian ini adalah untuk mengukur kualitas aplikasi gudang di PT. Unggul karya semesta. Instrumen penelitian yang digunakan adalah kuesioner yang hasilnya dihitung menggunakan rumus mean/ratarata untuk mengukur kualitas aplikasi gudang. Dari Hasil penelitian diketahui kualitas aplikasi gudang di PT.Unggul Karya Semesta dari parameter learnability diperoleh nilai 3,53 masuk dalam kategori baik, parameter efficiency diperoleh nilai 3,8 masuk dalam kategori baik, parameter memorability diperoleh nilai 3,81 masuk dalam kategori baik, parameter error diperoleh nilai 2,7 masuk dalam kategori cukup, parameter satisfaction diperoleh 3,71 masuk dalam kategori baik.
\end{abstract}

Kata kunci : usability, mean, aplikasi gudang

\section{PENDAHULUAN}

\section{A. Latar Belakang}

Persaingan bisnis yang semakin ketat, telah membuat banyak perusahaan harus berusaha lebih kerja keras agar dapat tetap bertahan didalam dunia bisnis yang serba 
dinamis. Perusahaan secara berkesinambungan mengatur ulang strategi dan kinerja dalam menghadapi persaingan bisnis tersebut perkembangan teknologi saat ini telah berkembang sedemikian cepatnya. Hal ini di rasakan dengan ada banyaknya perusahaan yang menggunakan aplikasi sebagai alat atau media untuk mempermudah manusia melakukan pekerjaannya dalam dunia bisnis, ketersediaan informasi yang cepat dan akurat dapat membantu perusahaan untuk terus berkreasi dan berinovasi meraih keunggulan yang kompetitif. Peran teknologi informasi tidak hanya dalam kegiatan oprasional tetapi juga dalam kegiatan perencanaan dan pemberdayaan sumber daya lain di dalam perusahaan, oleh karena itu penyediaan informasi yang terintegerasi dengan berbagai sub sistem pendukung lainnya sangat di perlukan.

Penerapan informasi berbasis aplikasi dalam dunia bisnis bukan saja menjadi pertimbangan penting. Melainkan sangat strategis berbagai jenis sistem informasi berbasis aplikasi kini semakin luas oleh berbagai jenis industri seluruh dunia. Perusahaan - perusahaan modern yang menghadapi persaingan yang semakin ketat, terdorong untuk meningkatkan performansi, efisiensi, efektifitas serta daya saingnya dengan manfaat sistem informasi(SI), (anita arifin,budianto,andreas Y 2010).

Begitu pula sistem informasi yang handal dibuat sesuai dengan kebutuhan yang ada, mudah digunakan, terintegerasi antar fitur yang satu dengan yang lainnya agar memudahkan pada saat penggunaan dan pengelolaan data yang diinput, diproses, sehingga menghaslkan output yang diinginkan.

Bahkan jogiyanto (2007p. 152) menyatakan bahwa usablity merupakan salah satu pengukuran kualitas sistem agar kesuksesan sistem informasi dapat terukur. Usability adalah suatu ukuran,dimana pengguna dapat mengakses fungsionalitas dari sebuah sistem dengan efektif, efisien, dan memuaskan dalam mencapai tujuan tertentu

Pengukur ini dapat mengunakan metode usability atau kebergunaan. Menurut jacob nielsen (2003), kebergunaan (usability) berdasarkan lima komponen yaitu learnibility, eficiency, memorability, errors, dan satisfaction .Berdasarkan uraian-uraian di atas maka akandilakukan pemetaan yang mengetahui untuk tingkat kualitas pada aplikasi gudang di PT. Unggul karya semesta”.

Sebelumnya Penelitian yang dilakukan oleh muhamad dwi insan khatulistiwa tahun 2015 dengan judul penerapan metode usability nielsen untuk mengetahui tingkat kualitas pada program metatrader, objek penelitian ini adalah para pengguna program metatrader 4, untuk mengetahui sebarapa besar kepuasan terhadap program metatrader 4 , seberapa besar kepuasan user dalam menggunakan program metatrader 4, dan seberapa besar pengaruh user terhadap program metatrader 4 . Karena terdapat fitur-fitur yang terdapat pada program metatrader 4 untuk memudahkan user dalam melakukan pemakaian 
program metatrader 4, tapi masih banyak user yang masih belum menggunakan fitur-fitur tersebut secara maximal.

\section{B. Rumusan Masalah}

Penggunaan aplikasi gudang PT. Unggul karya semesta digunakan untuk penerimaan barang atau bahan baku pada bagian inventory khususnya raw material.Pada tahap penerimaan barang dari supliyer semua barang yang masuk ke gudang akan di cek terlebih dahulu oleh penerima barang (receiving) untuk mengetahui apakah barang tersebut benar sama dengan yang tertera pada surat jalan, setelah di cek oleh penerima barang ( receiving) data barang yang masuk akan dimasukan kedalam sistem.

Berikut adalah tampilan aplikasi gudang di PT.unggul karya semesta Gambar 1.

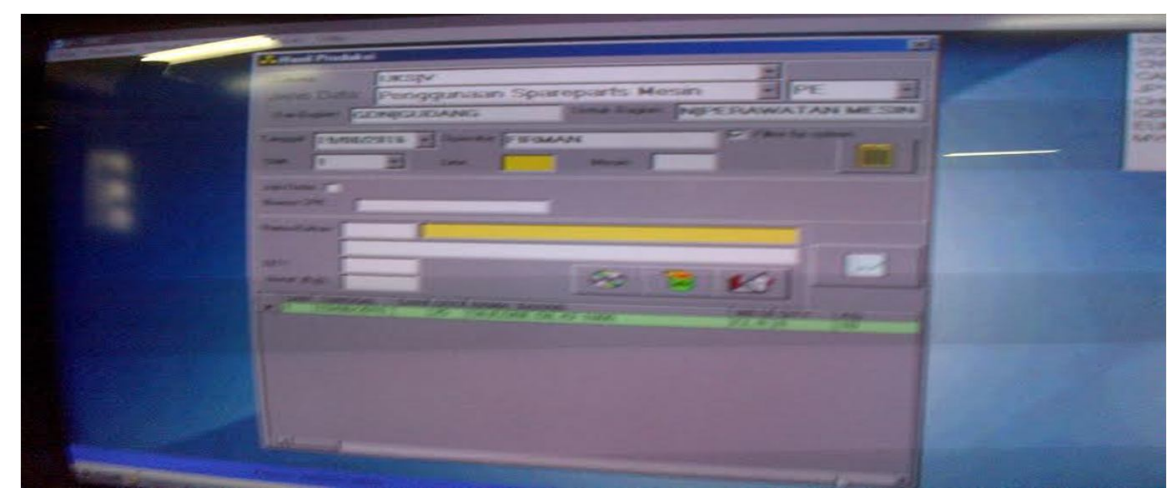

Gambar 1. Tampilan Aplikasi Gudang

Fungsi dari aplikasi ini adalah untuk memasukan data barang masuk dan data barang keluar, pada aplikasi ini proses penginputan data barang dilakukan dengan cara memasukan kode barang satu persatu, sehingga penginputan barang menjadi optimal , aplikasi gudang ini juga digunakan oleh bagian inventory untuk mengetahui jumlah stok barang yang diperlukan oleh bagian lain, namun pada saat dilakukan pemeriksaan oleh bagian inventory sering diperoleh kejadian jumlah barang yang terdapat disistem tidak sama dengan jumlah stok barang yang yang terdapat di gudang Selain permasalahan tersebut, juga sering terjadi kerusakan data pada aplikasi gudang .

Permasalah data yang eror, data line unmatch adalah data yang belum di verifikasi dengan document sedangkan line finish adalah data yang sudah selesai di check sesuai document, permasalahan yang sering terjadi adalah data stock dan data dokumen tidak sesuai dikarenakan barcode $\mathrm{S} / \mathrm{N}$ barang masuk tidak sesuai dengan barcode $\mathrm{S} / \mathrm{N}$ barang keluar dikarenakan sistem eror dan tidak bisa terditeksi saat sedang ingin mecari material/barang sehingga mengakibatkan stok inventory dan data aktual eror akibat adanya kesalahan barcode dan saat stock opname terjadi ketidak sesuaian antar data stok dan data dokumen. 


\section{Maksud Dan Tujuan Penelitian}

Maksud dari penelitian ini adalah menerapkan metode usability untuk mengukur kualitas aplikasi gudang di PT. Unggul karya semesta.

Tujuan dari penelitian ini adalah :

1. Mengetahui nilai learnability (kemudahan) pada aplikasi gudang di PT. Unggul karya semesta.

2. Mengetahui nilai afficiency (efisiensi) pada aplikasi gudang di PT. Unggul karya semesta.

3. Mengetahui nilai memorability (kemudahan untuk diingat) pada aplikasi gudang di PT. Unggul karya semesta.

4. Mengetahui nilai errors (kesalahan dan keamanan) pada aplikasi gudang di PT. Unggul karya semesta.

5. Mengetahui nilai satisfaction (kepuasan) pada aplikasi gudang di PT. Unggul karya semesta.

\section{Ruang Lingkup Dan Keterbatasan Penelitian}

Ruang lingkup penelitian adalah untuk mengetahui kualitas aplikasi gudang di PT. Unggul karya semesta dengan menggunakan 5 variabel pengukur usability yaitu learnability, effiency, memorability, errors, satisfaction. Adapun keterbatasan dari penelitian ini adalah pada jumlah responden yang digunakan sebanyak 20 orang responden, selain itu sumber data yang diperoleh dari PT.ungul karya semesta tidak dapat di tampilkan secara menyeluruh dan lebih rinci karena merupakan privasi perusahaan.

\section{METODE}

\section{A. Landasan Teori}

1. Sistem Informasi

Untuk menghasilkan informasi yang cepat dan akurat tentunya harus memiliki sistem informasi yang handal. Karena informasi merupakan data yang telah diproses kedalam suatu bentuk yang mempunyai arti bagi yang menerima dan mempunyai nilai nyata dan terasa bagi pengambilan keputusan saat itu atau keputusan yang akan datang, sedangkan sistem merupakan sekelompok unsur yang erat hubungannya satu dengan yang lainnya yang berfungsi bersama-sama untuk mencapai tujuan tertentu sutabri (2012, p.1-16).

Jadi Sutabri (2012, P.46) mengartikan sistem informasi sebagai sesuatu sistem dalam suatu organisasi yang mempertemukan kebutuhan pengolahan transaksi harian yang mendukung fungsi organisasi untuk dapat meyendiakan kepada pihak luar tertentu dengan laporan-laporan yang diperluakan. Sedangkan Al-jufri (2011, p.15) 
menyatakan bahwa yang dikatakan sistem informasi merupakan kombinasi dari orang-orang, fasilitas, teknologi, media prosedur, dan pengendalian yang ditujukan untuk mendapatkan jalur komunikasi penting, terhadapkejadian-kejadian internal dan eksternal dan menyediakan suatu dasar informasi untuk mengambil keputusan.

2. Teknologi Informasi

Istilah teknologi informasi diindetikan dengan komputer, teknologi komputer, atau pengolahan data elektronis.Dalam hal kadir (2005 p.2) menyatakan bahwa teknologi informasi adalah gabungan dari teknologi komputer dan tekonologi telekomunikasi.Komputer yang dimaksud terdiri dari perangkat lunak (software) dan perangkat keras (hardware) sedangkan teknologi komunikasi diartikan adanya jarak dalam menggunakan alat.Sehingga kaadir (2003, p.14) menyatakan bahwa lingkup teknologi informasi dikelompokan menjadi dua yaitu perangkat lunak yang terkait dengan intruksi-intruksi dan oerangkat keras yang terkait dengan perlatan fisik. Sedangkan Al-jufri (2011, p.38) menyatakan bahwa teknologi informasi digunakan untuk mengolah data, termasuk memproses, mendapatkan, menyusun, menyimpan, dan memanipulasi data dalam berbagai cara untuk mendapatkan inaformasi yang berkualitas, yaotu informasi yang relevan, akurat, dan tepat waktu pada saat digunakan.

3. Usability

Kajian tentang usability merupakan bagian dari bidang disiplin ilmu human computer interaction (HCI). Disampaikan oleh (nugroho:2009) human computer interaction merupakan bisang ilmu yang berkembang sejak tahun 1970 yang mempelajari bagaimana mendesain tampilan layar komputer dalam suaatu aplikasi sistem informasi agar nyaman digunakan oleh pengguna.usabilitty adalah tingkat kualitas dari sistem yang mudah dipelajari, mudah digunakan dan mendorong pengguna untuk menggunakan sistem sebagai alat bantu positif dalm menyelesaikan tugas. Untuk melihat sejauhmana kegunaan (usability) dari suatu produk itu dilihat dari manfaat pengguna dalam memanfaatkan fasilitas atau fitur yang ada pada suatu produk tersebut.Begitu pula sistem informasi yang handal dibuat sesuai dengan kebutuhan yang ada, mudah digunakan, terintegrasi antar fitur yang satu dengan yang lainnya agar memudahkan pada saat penggunaan dan pengelolaan data yang diinput, diproses, sehingga menghasilkan output yang diinginkan.

Bahkan jogiyanto (2007p.152) menyatakan bahwa usability meerupakan salah satu pengukuran kualitas sistem agar kesuksesan sistem informasi dapat terukur. Indikator usability menurut jakob nielsen seperti ditunjukan pada gambar 2 di bawah ini : 


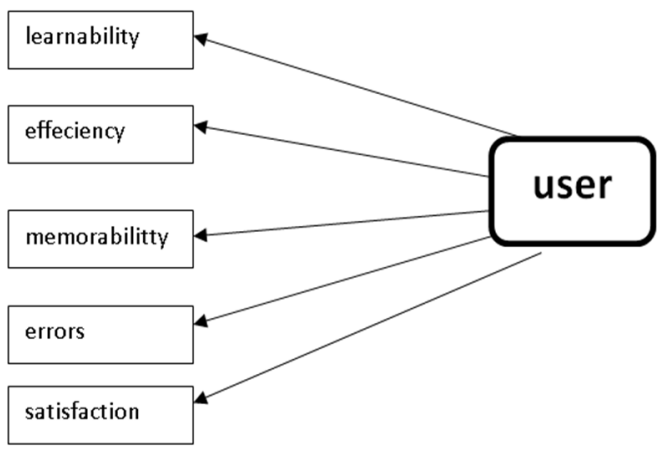

Gambar 2. indikator usability Nielsen

a. learnibility, menjelaskan tingkat kemudahan user untuk mempelajari sistem aplikasi guna menyelesaikan tugas.

b. Effeciency, menjelaskan seberapa cepat pengguna dapat menyelesaikan tugastugas dengan menggunakan sistem aplikasi

c. Memorability, menjelaskan tentang tingkat kemudahan user dalam mengingat sistem aplikasi dengan baik setelah beberapa lama tidak menggunakan.

d. Errors, menjelaskan kemungkinan terjadinya error atau kesalahan yang dilakukan oleh user dan seberapa mudah mengatasinya.

e. Satisfaction, menjelaskan tentang tingkat kepuasan pengguna dalam menggunakan aplikasi yang telah dibuat.

Menurut international standart organization (ISO) 9241, usability adalah efektifitas dalam pemakaian, efesien dalam sumber daya, dan kepuasan yang didapatkan pengguna dalam menyelesaikan suatu pekerjaan, dalam sabuah lingkungan dari sebuah produk. Menurut joseph dumas dan janice redih dalam bukunya yang berjudul A practical guide to usability testing, 1999, usabilitydigunakan untuk mengukur tingkat pengalaman pengguna ketika berinteraksi dengan produk sistem, baik itu website, software, mmobile phone maupun peralatan yang digunkan pengguna lainnya. Menurut nielsen dalam artikel yang berjudul "Guerrila HCI: using dicount usabilitty Engineering to penetrate the intimidation barrier" (nielsen, 1994), definisi usability sebagai suatu pengalaman pengguna dalam berinteraksi.

Dengan aplikasi atau situs web sampai pengguna dapat mengoprasikannya dengan mudah dan cepat. Secara umum, usability mengacu pengguna bisa mempelajari dan menggunakan produk untuk memproleh tujuannya dan seberapa setujukah mereka terhadap penggunaanya.

Setelah melakukan kajian tentang usability secara umum, maka selanjutnya perlu dilakukan kajian bagaimana melakukan pengukuran usability pada website. Secara 
umum kriteria yang menentukan bahwa sebuah website usable (memiliki tingkat usability yang tinggi) adalah apabila pengguna bisa menemukan atau memeperoleh apa yang mereka butuhkan dan mengerti dari website tersebut.

\section{B. Kerangka Pemikiran}

Penelitian ini dilakukan untuk mengukur tingkat kualitas dari aplikasi gudang dengan menggunakan metode usability nielsen, adapun kerangka pemikiran penelitian ini seperti ditunjukan pada gambar 3 .

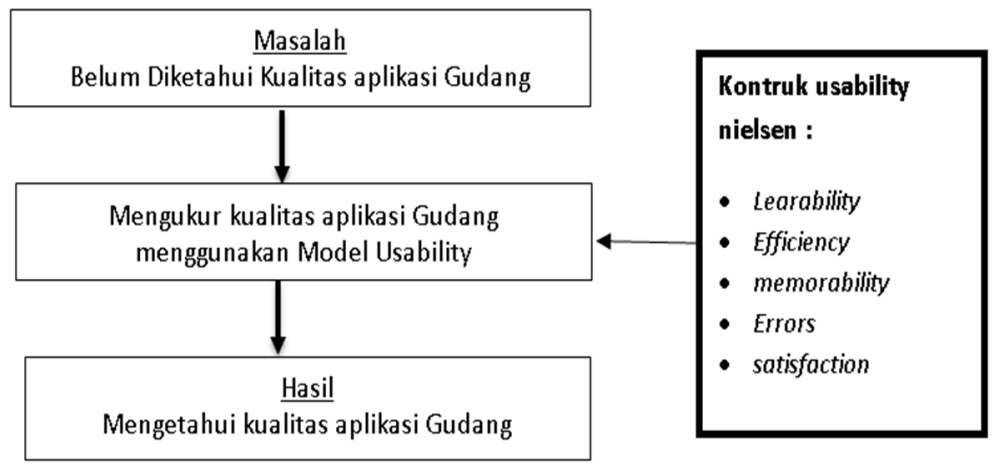

Gambar 3 . Kerangka Pemikiran

Dari gambar 3 diatas dapat diuraikan bahwa penelitian dimulai dengan melakukan identifikasi masalah, yaitu mencari perumusan masalah tentang perilaku pengguna terhadap penerimaan pengguna terhadap aplikasi gudang. Kemudian penelitian menggunakan pendekatan metode usability nielsen dengan memasukan beberapa variabel pada usability nielsen antara lain: learnability, efficiency, memorability, efficiency, memorability, errors, satisfaction untuk dijadikan sebagai alat ukur terhadap masalah yang ada.

Setelah menetapkan beberapa variabel dari usability nielsen, selanjutnya penelitian membuat koesioner dan menyebarkannya kepada sejumlah responden yang telah ditetapkan yaitu user dari pengguna aplikasi gudang di PT. Unggul kaya semesta. setelah itu koesioner dikumpulkan kembali dan dilakukan analisis data menggunakan rumus ratarata. Kemudian, setelah analisis dan perhitungan selesai dapat diperoleh hasil dari analisis data yang akan dijadikan kesimpulan dan saran dari penelitian ini

\section{HASIL DAN PEMBAHASAN}

A. Hasil Penelitian

Untuk mencapai kualitas prima setiap mulai dari resin hingga barang jadi , dengan penuh persiapan. Karyawan kami yang berpengalaman memperhatikan setiap langkah produksi dengan penuh keseriusan untuk memenuhi standar kualitas dan ketepatan waktu dalam pengiriman. Aplikasi gudang merupakan aplikasi yang diperuntukan untuk para 
karyawan PT. unggul karya semesta yang di gunakan untuk memasukan data barang masuk dan keluar konten-konten yang berhubungan informasi data barang di aplikasi gudang tersebut meliputi kode barang, Data barangi, supliyer, dan tgl masuk dan keluarnya barang. Salah satu kegunaan aplikasi ini adalah untuk mengontrol data barang yang keluar dan masuk.

1. Responden

Untuk mengambil sumber data yang akan di olah, maka diperlukan kuesioner yang diberikan kepada responden yang ada dilingkungan perusahaan yang akan di teliti. Penyebaran kuesioner dilakukan kepada tenaga kerja yang berjumlah 18 orang di tamabah staf IT berjumlah 2 orang.

2. Hasil Kuisioner

pada tahap ini diperoleh data hasil kuesioner yang akan di analisis. Tabulasi kuesioner dapat dilihat pada tabel 1

Tabel 1. Tabulasi Kuisioner

\begin{tabular}{|c|c|c|c|c|c|c|c|c|c|c|c|c|c|c|c|c|c|c|}
\hline \multirow{3}{*}{$\begin{array}{l}\text { Respo } \\
\text { nden }\end{array}$} & \multicolumn{4}{|c|}{$\begin{array}{c}\mathrm{L} \\
\left(X_{1}\right)\end{array}$} & \multicolumn{3}{|c|}{$\begin{array}{c}E \\
(X 2)\end{array}$} & \multicolumn{4}{|c|}{$\begin{array}{c}M \\
\left(X_{3}\right)\end{array}$} & \multicolumn{4}{|c|}{$\begin{array}{l}E R \\
(X 4)\end{array}$} & \multicolumn{3}{|c|}{$\begin{array}{l}\text { SAT } \\
\text { (V1) }\end{array}$} \\
\hline & $\mathrm{x}$ & $x$ & $x$ & $x$ & $x$ & $x$ & $\mathrm{x}$ & $x$ & $\mathrm{x}$ & $\mathrm{x}$ & $x$ & $x$ & $x$ & $x$ & $x$ & $x$ & $x$ & $x$ \\
\hline & 11 & 12 & 13 & 14 & 21 & 22 & 23 & 31 & 32 & 33 & 34 & 41 & 42 & 43 & 44 & 51 & 52 & 53 \\
\hline 1 & 5 & 4 & 4 & 4 & 4 & 4 & 4 & 5 & 5 & 5 & 4 & 1 & 3 & 3 & 3 & 5 & 5 & 3 \\
\hline 2 & 5 & 4 & 2 & 5 & 5 & 5 & 4 & 4 & 4 & 5 & 5 & 3 & 3 & 2 & 3 & 5 & 5 & 4 \\
\hline 3 & 4 & 4 & 4 & 4 & 4 & 3 & 3 & 4 & 4 & 4 & 4 & 3 & 2 & 3 & 2 & 4 & 4 & 4 \\
\hline 4 & 4 & 5 & 3 & 5 & 5 & 4 & 4 & 3 & 4 & 3 & 4 & 3 & 3 & 3 & 3 & 5 & 4 & 3 \\
\hline 5 & 5 & 4 & 4 & 4 & 4 & 4 & 4 & 4 & 4 & 4 & 5 & 3 & 3 & 2 & 3 & 4 & 4 & 4 \\
\hline 6 & 4 & 4 & 3 & 5 & 4 & 4 & 4 & 4 & 4 & 4 & 4 & 3 & 3 & 3 & 3 & 4 & 4 & 3 \\
\hline 7 & 4 & 4 & 4 & 4 & 4 & 4 & 4 & 5 & 3 & 3 & 4 & 2 & 2 & 2 & 3 & 3 & 4 & 3 \\
\hline 8 & 4 & 5 & 4 & 5 & 4 & 5 & 5 & 5 & 4 & 4 & 3 & 3 & 3 & 2 & 3 & 4 & 4 & 5 \\
\hline 9 & 4 & 4 & 3 & 4 & 4 & 4 & 5 & 4 & 3 & 4 & 3 & 3 & 3 & 3 & 2 & 3 & 4 & 3 \\
\hline 10 & 5 & 3 & 3 & 5 & 5 & 4 & 2 & 4 & 4 & 5 & 5 & 3 & 3 & 3 & 3 & 5 & 5 & 3 \\
\hline 11 & 4 & 2 & 2 & 4 & 2 & 3 & 4 & 3 & 3 & 4 & 4 & 2 & 3 & 2 & 3 & 4 & 4 & 4 \\
\hline 12 & 5 & 3 & 4 & 4 & 2 & 4 & 4 & 5 & 3 & 5 & 4 & 3 & 3 & 3 & 3 & 5 & 5 & 5 \\
\hline 13 & 4 & 2 & 2 & 5 & 3 & 5 & 4 & 4 & 4 & 4 & 3 & 3 & 3 & 3 & 3 & 4 & 4 & 5 \\
\hline 14 & 3 & 2 & 4 & 5 & 3 & 5 & 3 & 4 & 4 & 3 & 4 & 2 & 2 & 3 & 2 & 5 & 3 & 5 \\
\hline 15 & 3 & 3 & 3 & 4 & 4 & 4 & 4 & 4 & 4 & 3 & 3 & 3 & 3 & 3 & 3 & 3 & 3 & 3 \\
\hline 16 & 3 & 1 & 3 & 1 & 3 & 4 & 3 & 5 & 3 & 3 & 4 & 3 & 3 & 2 & 3 & 3 & 3 & 3 \\
\hline 17 & 3 & 3 & 3 & 3 & 2 & 5 & 3 & 4 & 4 & 3 & 4 & 2 & 2 & 2 & 2 & 3 & 3 & 2 \\
\hline 18 & 3 & 2 & 2 & 2 & 2 & 2 & 3 & 3 & 3 & 3 & 4 & 3 & 3 & 3 & 3 & 3 & 3 & 3 \\
\hline 19 & 3 & 3 & 3 & 5 & 2 & 4 & 4 & 4 & 4 & 3 & 3 & 3 & 2 & 2 & 2 & 3 & 3 & 3 \\
\hline 20 & 2 & 2 & 2 & 2 & 4 & 3 & 2 & 3 & 2 & 2 & 3 & 3 & 3 & 3 & 3 & 2 & 2 & 2 \\
\hline
\end{tabular}

B. Pembahasan

Hasil pengukuran kualitas aplikasi gudang untuk semua variabel usability dapat dilihat pada tabel 2 .

Pada tabel 2 dapat diketahui kualitas aplikasi gudang di PT. Unggul karya semesta untuk setiap parameter, untuk parameter learnability dengan nilai 3,53 yaitu baik, parameter efficiency dengan nilai 3,7 yaitu baik, parameter memorability dengan nilai 
3,81 yaitu baik, parameter error dengan nilai 2,7 yaitu cukup, parameter satisfaction 3,71 yaitu baik. Tabel 2. Hasil Nilai rata-rata parameter usability

\begin{tabular}{|c|c|c|c|}
\hline NO & PARAMETER & RATA-RATA & KATEGORI \\
\hline 1 & Learnability & 3,53 & Baik \\
\hline 2 & Effeciency & 3,7 & Baik \\
\hline 3 & Memorability & 3,81 & Baik \\
\hline 4 & Error & 2,7 & cukup \\
\hline 5 & Satisfaction & 3,71 & Baik \\
\hline
\end{tabular}

Berdasarkan hasil pengukuran untuk mengukur kualitas aplikasi gudang dalam penelitian ini bahwa kriteria error merupakan yang paling rendah nilai rata-ratanya yaitu 2,7. Kriteria memorability merupakan yang paling tinggi nilai rata-ratanya yaitu sebesar 3,81 .

Adapun grafik hasil ukur kualitas apliaksi gudang di PT. Unggul karya semesta dapat dilihat pada Gambar 4.

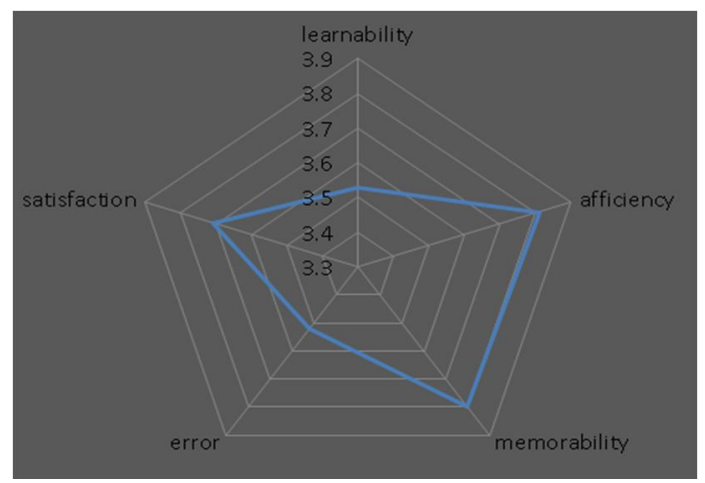

Gambar 4. Grafik Hasil Ukur

\section{KESIMPULAN DAN SARAN}

\section{A. Kesimpulan}

Dengan menggunakan metode usability yang terdiri dari variabel learnability, variabel efficiency, variabel memorability, variabel error dan variabel satisfaction dapat diketahui nilai usability aplikasi gudang di PT. Unggul karya semesta, adalah sebagai berikut.

1. Nilai learnability pada aplikasi gudang di PT. Unggul karya semesta sebesar 3,52 Dengan kategori baik, artinya pengguna menilai dari sisi learnability (kemudahan mempelajari) aplikasi gudang sudah baik.

2. Nilai efficiency pada aplikasi gudang di PT. Unggul karya semesta sebesar 3,7 Dengan kategori baik, artinya pengguna menilai dari sisi efficiency (efisiensi) aplikasi gudang sudah baik.

3. Nilai memorability pada aplikasi gudang di PT. Unggul karya semesta sebesar 3,81 Dengan kategori baik, artinya pengguna menilai dari sisi memorability (kemudahan untuk mengingat) aplikasi gudang sudah baik. 
Jurnal IImiah Teknologi - Informasi dan Sains (TeknolS)

Volume 7 Nomor 1 Bulan M ei 2017

p-ISSN : 2087-3891 dan e-ISSN : 2597-8918

4. Nilai error pada aplikasi gudang di PT. Unggul karya semesta sebesar 2,7 Dengan kategori cukup, artinya pengguna menilai dari sisi error, (kesalahan) aplikasi gudang sudah cukup

5. Nilai satisfaction pada aplikasi gudang di PT. Unggul karya semesta sebesar 3,52 Dengan kategori baik, artinya pengguna menilai dari sisi satisfaction, aplikasi gudang sudah baik.

\section{B. Saran}

Untuk pengembangan lebih lanjut, peneliti memberikan beberapa saran yang dapat dipertimbangkan, saran-saran tersebut sebagai berikut :

1. Menggunakan hipotesis untuk mengetahui kolerasi atau pengaruh dimensi usability dengan variabel lain contohnya dengan tingkat penerimaan penggunaan aplikasi.

2. Menggunakan metode statistik lain untuk mengetahui nilai setiap parameter.

\section{DAFTAR RUJUKAN}

$\mathrm{Al}$ - juri, Hamid, 2011. Sistem informasi manajemen pendidikan. Smart grafika, jakarta.

Hadi prayoga, (2010) usability pada aplikasi berbasis web dengan mengadopsi model kepuasan pengguna atau user satisfaction

Jogiyanto, HM. Akt, Ph.D. 2008. Metodologi penelitian sistem informasi. Andi jakarta.

Jogiyanto, HM. Akt.,MBA.,Ph.D 2007. Model kesuksesan sistem teknologi informasi. Yogyakarta: andi yogyakarta

Kasir, Abdul, 2003. Pengenalan sistem informasi. CV. Andi offset, yogyakarta

Lia suprapti, 2015. Penerapan usability untuk pemetaan web e-learning quipper school di smk budiniah

Muhammad dwi, 2010. Penerapan metode usability nielsen untuk tingkat kualitas pada program metatrader

Nopi apriandi, 2014. Pendekatan usability pada konsep human computer interaction (hci) untuk mengukur ketercapaian pembelajaran visual "power point" pada mata diklat powertrain di smk bina warga 1 kota bogor

Sugiyono,2013. Metode penelitian pendidikan. Lafabeta, bandung

Wahyu hidayat, 2003. Penerapan usability testing pada evaluasi situs web pemerintahan kota prabumulih 